\title{
Heartprint: Acoustic Tactics to Tune in Within Each Other
}

\author{
Angélica Yaneth Piedrahita Delgado \\ Department of Arts. Universidad de Monterrey UDEM \\ Av. Morones Prieto 4500 PTE, San Pedro Garza Garcia, \\ N.L. México, C.P. 66238 \\ angelica.piedrahita@udem.edu
}

\author{
Erick Vazquez Camarillo \\ Independent critic and curator \\ Priv. Liendo 709. Col Obispado, Monterrey \\ N.L. México, C.P. 64060 \\ erick.vazquez@gmail.com
}

\begin{abstract}
The paper proposes an acoustic approach to matters of the heart, attempting to fill the insufficiencies of language to correlate the organ's functions within affective health. This paper describes the research process and the theoretical background that followed to produce the art project Heartprint Acoustic Practice. It attempts to discuss the cultural and historical contexts of auscultation practices as well as the separation between cardiologic research, affectivity and the aesthetics of the heart reflected in nowadays emphasis on the brain, rather than the heart, as the organ and site of emotion. The project, as well as this article, advocates for a phenomenological approach to understand the correlation between an individual's heart health in a broader sense, and the way human beings recognize each other's inner states.
\end{abstract}

Heartbeat. Auscultation. Sounding bodies. Art clinics.

\section{INTRODUCTION}

With Heartprint: Acoustic Tactics to Tune with Each Other, we propose reconciliations between the aesthetical and the functional model of the heart through listening sessions. The project offers an acoustic approach to matters of the heart, attempting to fill the insufficiencies of language to correlate the organ's function within affective health. By following a need to convey deep layers of affection, and by avoiding verbal miscommunication, we suggest new ways in recognizing individuals through attentive listening of cardiac rhythms, frequencies and harmonic cues. The project allows a dynamic, in which by listening participants live mixed heartbeats we disclose a sum of singularities that reveals an irreducibly animal embraced musical existence, therefore an aesthetical being.

Since 2018, we have been conducting auscultation practices, which consist of attentive hearing clinics in which cardiac rhythms are documented in order to conduct research on the wide perception of the heart as an organ, as much as a symbol of affection. During the clinics, we approach emotional dimensions by means of an attentive listening that allows participants to hear their own beating organ in a group activity. During the first months of these clinics, we developed private sessions in which participants heard their own heart sounds amplified (figure 1). Meanwhile, they describe their emotional self care routines; ways in which they maintain a healthy emotional balance. Afterwards, we set up public, open sessions, where families hear their

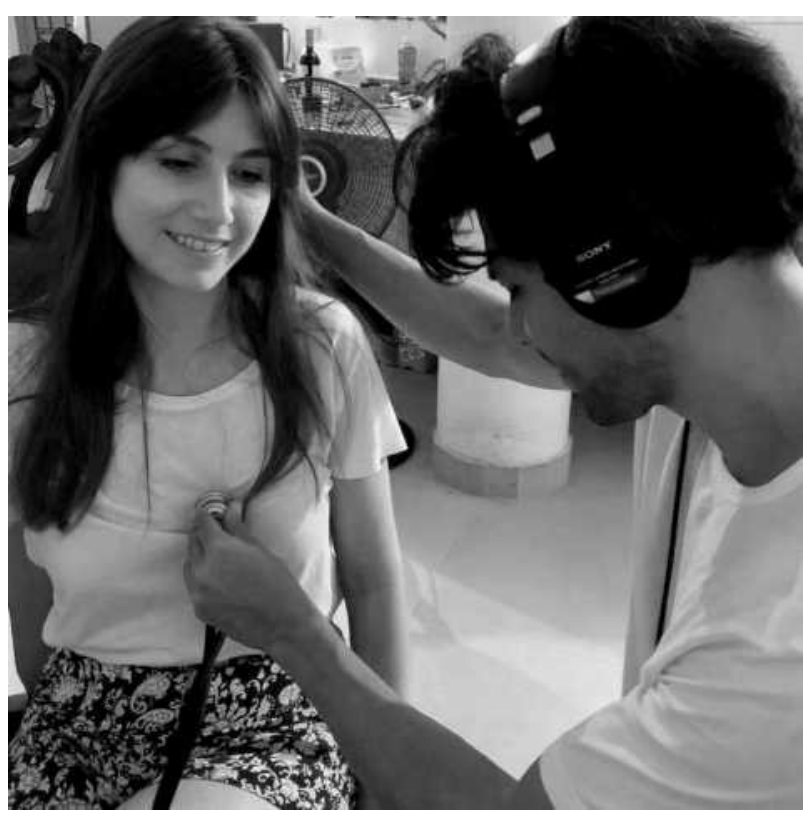

Figure 1: First private clinics, at the artist's house. 2018

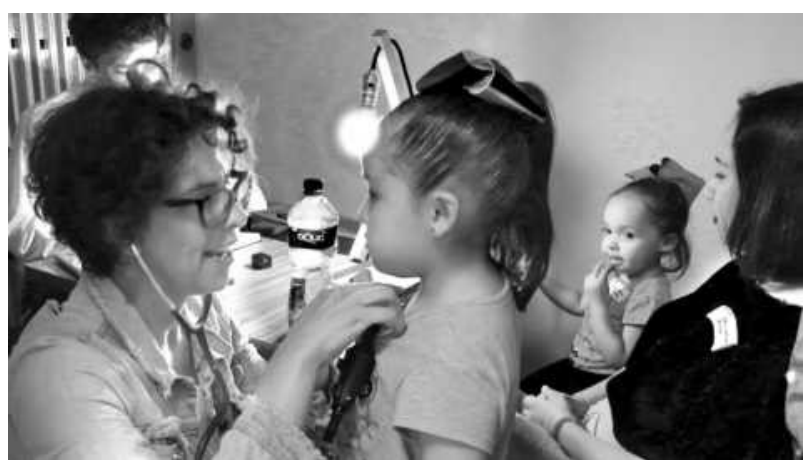

Figure 2: First public clinics in family groups at FEMSA collection activities. 2018 
hearts as a group experience (figure 2). Along these clinical studies we discovered a correlation between the acoustic representations of the heartbeat and the character of the individual. This heartprints - as we decided to name them showed sound layers specific to each person. Our understanding of the heartprints grew stronger, as our listening skills became more and more sensitive to the murmurs, turbulence and basic sounds of the heart valves. In 2019, the clinics transformed into a micro-theater performance, where participants, aided with headphones, heard each others' heartbeats as well as their own mixed heartbeats, transmitted by a shortwave radio transmitter. This allowed us to discreetly weave participant's understandings of their own heart sounds in relation to others (figures $3,4,5$ ), acknowledging the subtle differences between each heartprint.

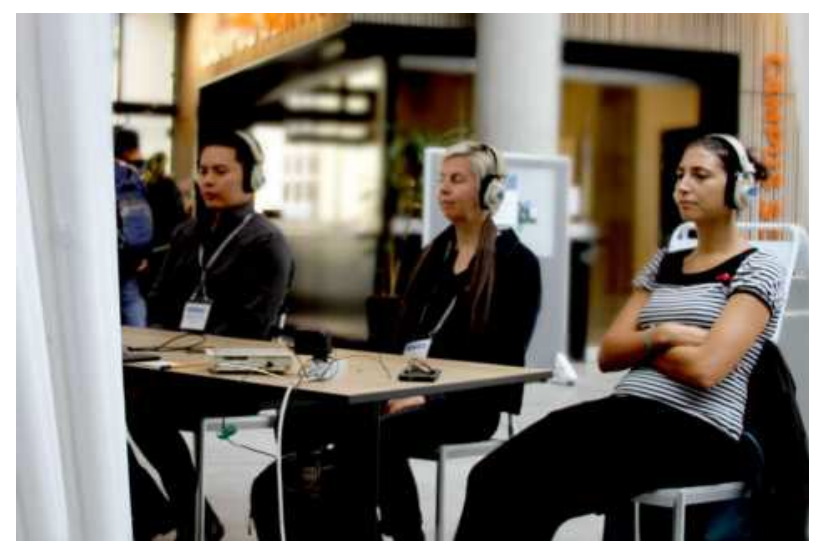

Figure 3: Live radio transmission of mixed heartbeats. 2019

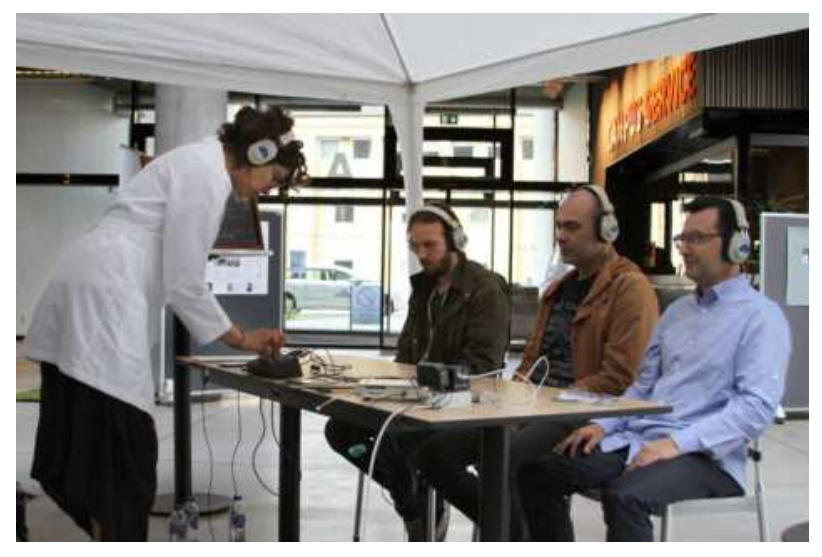

Figure 4: Live radio transmission of mixed heartbeats. 2019

\section{AUSCULTATION, HEARING PRACTICES AND CARDIOLOGY'S ACCOUNTS}

The nineteenth century gave birth to the experience of listening as an art form. In cardiology, Dr Jean

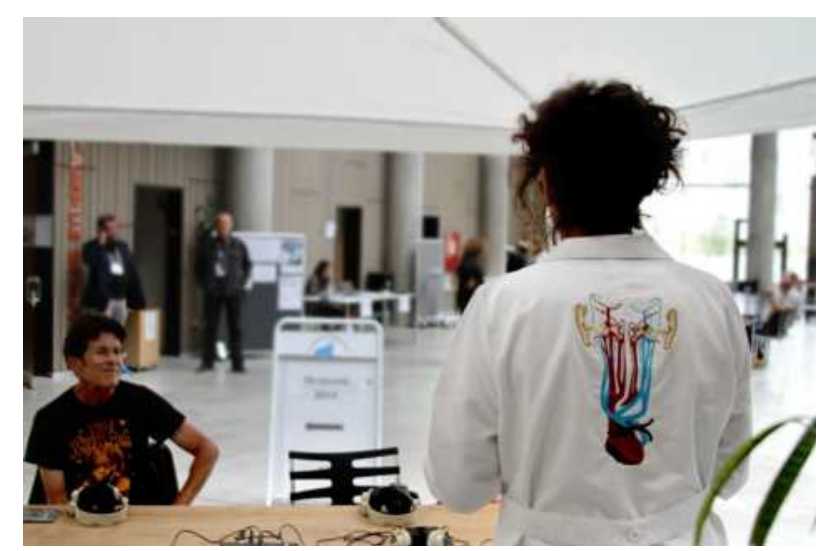

Figure 5: Intervened lab coats as part of the clinic sessions

Nicolas Corvisart became famous at the Collège de France for studying and perfecting the ancient technique of chest percussion as a diagnostic tool. His relevance in cardiology's history is a result of his vigorous work in shifting the research from autopsy to clinical research. As a teacher, he promoted a conscious practice of listening, not only of patient's hearts, but also to the patient's narration of their symptoms. For Corvisart (1812 p.19), "a physician must sedulously apply himself both to the physical and moral man" He/she must perceive the most delicate perceptible influence of the reciprocal action of the one over the other. Additionally, Corvisart's student René T.

$\mathrm{H}$. Laennec helped shape the art of clinical diagnosis of the heart and chest, through mediate auscultation with his stethoscope. By early 1817, the device was widely used for cardiac auscultation; aesthetic sonic experiences were important part of diagnosis. To instruct mediated auscultation, Laennec (1827) used metaphors to describe the sound that convey each heart's movements, for example, he uses the image of a whip and the lapping of a dog, as characteristic of the contraction of the auricles, followed by an interrupting silence in a normal heart valve noise.

Medical and cultural history of the heart has a long affiliation with affections, having a drastic change during the 19th century, as a result of cognitive and psychological research. However, it strikes us that in religious, symbolic, linguistic and philosophical fields we maintain a deep complex relationship between the heart, the self and the act of affection in spite of science. Representations of the vascular organ and it's graphic abstractions are embedded to inner and complex emotions in western poetry, as well as, quotidian use of language. We acknowledge that in the last two centuries, heart and brain had been quarreling where the heart hastens to move according to emotions, while the brain, acts upon a complex set of causalities and consequences. It is clear to us that popular language keeps dismembering the organs: one as 
the place of profound feelings of love and empathy and the other one as the core of the nervous system.

Fay Bound (2010) tracks a medical history of the heart and the emotions from Greek medical research. In her book Matters of the Heart: History, Medicine and Emotions, she tracks down how in humoral physiology, the body and the soul were indivisible. Even after the decline of humoralism, we keep describing individuals as cold hearted or hot blooded, and experiences as heart-warming, heartening, or even heartfelt. In modern medical terms, the heart is abstracted from the model, and its actions are determined by electrical impulses. Blood vessels, and all the body's organs are explained through the actions of the autonomic nervous system that conveys impulses to the brain. According to Bound, this complex mechanistic view of the heart in terms of hydraulic and electrical terms, took a long path in cardiology research that started with William Harvey's discovery of blood circulation in 1628. This mechanistic view passed through a set of principles and maps that abandoned humoralism beliefs, pursuing anatomic and pathological research, finally gaining a concrete understanding by early 19th century with medical and clinical practices like the ones of Corvisart and Laennec.

Modern-day emphasis on the brain, rather than the heart as the organ and site of emotion, is marked by a transition from a cardio-centric to a craniocentric body, largely unexplored as an aspect of the history of psychology but evident in the history of cardiology. The change in the model fails to provide a way to understand modern ambivalence towards the heart, as an affection symbol as well as a functional organ. The transformed model neglects the weight and perseverance of the networks of meanings — spiritual, medical, psychological, and physiological- in which it has historically been embedded. The cardiac model can only store a limited amount of information, if it exceeds turns unreadable and not functional, and compartmentalization ends up being necessary. The current known map of the central and peripheral nervous system linked to the endocrine system, recognizes at the molecular level an auto regulated model; endocrine disruptors as well as hormonal imbalances can be somewhat auto regulated. The endocrine map connects to the brain through the central nervous system, however not every hormonal or endocrine disorder is treated through the brain. Our point here is to highlight the dissection of the body map used in medical practice, understanding that even if we perceive the central nervous system as in control of most of our body processes, the mind at times will have nothing to do with this schema. The model of the central nervous system, where the mind is in the brain, doesn't consent cardiology research history anywhere in the schema.

\section{PHENOMENOLOGICAL AND AESTHETICAL APPROACHES}

The formation of the world through living experiences has been something clear for philosophy and other humanities. Phenomenology, for instance, acknowledges the conjunction of sensory processes and intersubjective models. Sociology, anthropology and aesthetics explore the relations within our closest social circles adapted, reinforced or created through aesthetic expressions such as music, art and literature. Cognitive sciences welcomed the concept of involuntary memory as complex phenomena that activate mental images thanks to the detailed descriptions of Proust (Delacour, 2001). Mind sciences also need a holistic review of biochemistry and ecology to describe new models of the body. However, in favor of a functional map of the different body processes, every system ends up being disembodied even when inter or transdisciplinary research is allowed. In Eye and Mind (1964) for instance, Maurice Merleau-Ponty objects the scheme in which science understands the body, confronting it to individual experience. His text is a comprehensive yet abstract way to describe the experience of living in a human body, entering in the realm of metaphysics, however an exquisite way to describe the bodily process of painting beyond the semantics implied in art practice. Describing the embodied experience of painting, seems impractical, however it approaches the common language of physiological optics in terms of aesthetic experience and this translation helps to expand the model of vision as a corporeal model in which the eye is not an unaffected element that observes the world, but one that is constituted by it, thinking about sensing and existing.

\footnotetext{
"This initial paradox cannot but produce others. Visible and mobile, my body is a thing among things; it is one of them. It is caught in the fabric of the world, and its cohesion is that of a thing. But because it moves itself and sees, it holds things in a circle around itself. Things are an annex or prolongation of itself; they are encrusted in its flesh, they are part of its full definition; the world is made of the very stuff of the body". (Merleau-Ponty, 1964, p 3)
}

Merleau-Ponty's thoughts are parallel to a practical medical example of the Kangaroo Mother Care Method', which recognizes that during the 2nd month of pregnancy the brain, spinal cord and other neural tissue of the central nervous system are well formed and sensory organs begin to develop. For researchers related to the method, it is not absurd to believe that for some premature born babies, being close to their mom's chest 
would be more beneficial than isolation from their world (mother's womb) in an incubator. This ensures physiological and psychological warmth and bonding. It provides a physical closeness that keeps the new-born connected to another human's peripheral nervous system, giving the mother as well as the baby, different benefits, some of them still in research that examines child cardiac problems in responses to a KC experiences (Cong, X., Ludington, S., McCain, G. and Fu, P. 2009; MacCain, G., Ludington-Hoe, S., Swinth, J., and Hadeed, A. 2005). Phenomenologists as MerleauPonty consider the flesh as the membrane that gives visibility to the world. For them, this interaction goes both ways; the world is as known as affected by this flesh; an approach not far from molecular biology and biochemical research.

In spite of the time, the heart has been understood as an object that can be transplanted, repaired, and reproduced. The idea of being replaceable seems problematic in juridical figures as well as in philosophy. The French philosopher Jean Luc Nancy in 1999, wrote The Intruder as a way to describe the problematic figure of the other in medical transplants. An essay that, beyond the critiques on bio politics and our modern life's expectancy, narrates a process in which the body adapts to the new organ, and also the organ adapts to its new body. Through the process, Nancy questions the idea of self by questioning the immune system; arguing with the way in which his body and someone's heart are fighting for each other's integrity. At the end of his process and his text, the author claims that what he called the "I" withdraws to an infinite distance, to an intimacy more profound than any interiority. However this interior also connected to his body corpus meum and interior intimo meo, expose the truth of the subject composed by its exteriority as an infinite exposition. For Nancy, I' intrus organ exposed him, and at the same time helps him to realize that he is the illness as the medical intervention, the immunedepressive agent as their palliatives.

\footnotetext{
"I am the bits of wire that holds together my sternum, and I am this injection site permanently stitched in below my clavicle, just as I was already these screws in my hip and this plate in my groin". (Nancy, 2002 p. 13)
}

The heart, in its experience as a pulse that agitates and relaxes, in its medical knowledge field, as in its metaphorical figures in literature, is a unique case where both organ and sign are indistinct from each other. It is an exemplary case that effortlessly unifies science, arts and common knowledge with the heavy proof of a pound of flesh and the consistent poetry of the centuries. Popular sayings and highbrow literature on this subject matter preserve the very same sense and haven't changed throughout history, even as medical science advancement confirms the sayings of Shakespeare (1564-1616): "Tell me where is fancy bred, Or in the heart, or in the head?" As heart transplants are made possible, the philosopher's mind is unchanged, and confirms the belief that one's own heart is only owned as it is another's and what is inside can only be found outside.

Nevertheless, the heart is hidden in classic Latin by way of metonymic figures. The heart was simply called pectoris, naming what could come from the breast, the heart, or the mind indistinctively. What conceals the heart can only be known through words or by placing our ears to the chest, the heart has an acoustical image; we know it through our ears. In the relation between hearts and ears lies the problem of conceiving the heart as an object of intimacy, something that is not public, that could only be known by the way of the word in the grain of its frequency, its sound, getting inside another's body through the cochlea, a labyrinth where one could justly be lost rather than found; the meaning of desire itself, lost somewhere between a lub dub and a hammer that echoes the repercussions of another existence. Maybe, if the heart could only have a corporeal orifice, a direct mouth or an anus, a nose, a set of pores, but as it hasn't any, we need a technique, a discipline, an extension of the ear and an amplifier of the organ enclosed in the thoracic black box. Listening is an art, and through art we pretend to give a sort of form by way of question and answer.

The heart has its own electrical system, it works with actual independence from the brain and if removed from the body keeps pumping for a rather surprisingly extended amount of time. The fact that reason and feelings are in a physiological and symbolic struggle is shown in that it can be resolved by means of chemical drugs or thought process techniques as psychoanalysis _or a good, hearty talk with our meaningful ones-. This very material and symbolic independence allows us to follow the hearts vestiges and translate it's heartprint: it's singular identity.

The exact location of the self cannot be pinpointed, but the exact location of the residence of the heart is anatomically correct at least since the seventeenth century with Harvey. We still quite don't know what we are listening to, we know that it is a matter of certain urgency, and that it involves the meeting of apparently opposite fields of knowledge. But isn't it amazing that the answer is anatomically, if not symbolically, inside us? As Kant said on the foundations of The Critique of Pure Reason (1781) "I don't have to look very far, since I can find it in myself'"ii. But then again, it isn't, because as soon as one listens to its own heart it is already another's, there is just no way one can experience the beatings of their own heart as once 


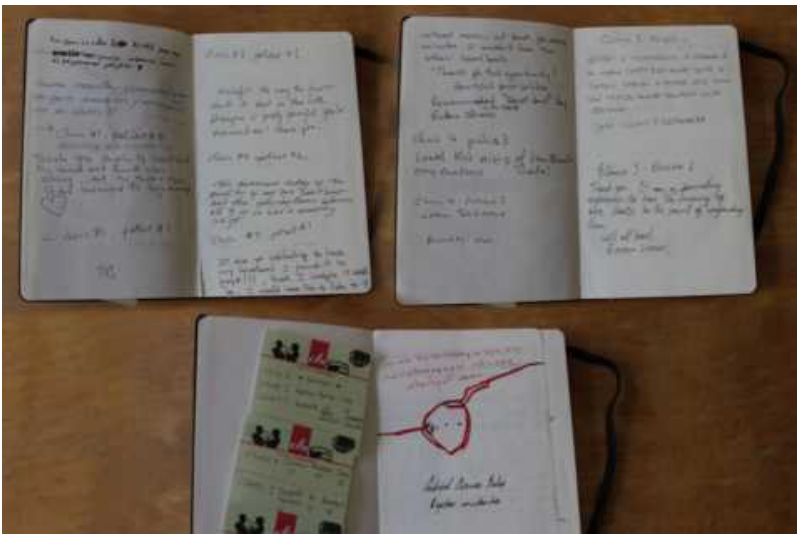

Figure 6: Participants book of visit. 2019

property and domain, and it's a singular experience as it is listening to one's voice in a recording (p.169).

\section{CLINICS AND THE EXPERIENCE OF HEARING THE SELF THROUGH THE BEAT}

On the first two types of clinics: private sessions (figure 1) and family sessions (figure 2), our presence seems to direct people's experience hearing their heartbeats. The framed interaction was akin to the doctor-patient relationship. So each time we finished the auscultation, individuals approached us in order to unfold the supposed hidden meanings behind the sound. For us there was an ethical concern regarding the way our audience would interpret our perception of their sound due to our lack of medical training. However, on our last clinics (figures 3, 4, 5), the framed interaction changed and we were no longer situated in the doctor-patient dynamic, but in a more opened experience in which by listening to other's heartbeats, individuals could experience their most profound interior self. There was no need to approach the doctor figure to understand the hidden layers of heartbeat. The practice of listening to their own heart in parallel to other's asserted Laennec's interests in how the aesthetic sonic experience was an important part of diagnoses. However this diagnoses can't be done without experiencing just one heartbeat; the other's reference is a way to understand mine. As if the other constitutes my own reflection.

One of the patient's wrote in our guest book: "This awareness today of the quality of my own heart beat and the polyrhythms between all 3 of us was a necessary insight". Meaning that it wasn't just the experience of hearing her own heartbeat, but the experience of hearing all of the patients heartbeats mixed, that helped her to point out the singularities of her own in relationship with her emotional state. Her experience was expressed in depth later on in a conversation with us, in which as a sound artist herself, familiar to describing the complex layers of sound, could point out the delicate textures of each patient's murmurs. Other patients also related their emotional and physical states with the sounds heard, understanding the fine relationship between our nervous system, emotional states and sound appreciation. It is essential for medical practice to understand the complexities of a heartbeat, for us is a way to expose the possibilities of sound art practice in self-care.

\section{REFERENCES}

Bound, A. F. (2010). Matters of the heart : History, medicine, and emotion. Retrieved from http://ebookcentral.proquest.com

Corvisart, Jean Nicolas (1812) An Essay on the Organic Diseases and Lesions of the Heart and Great Vessels, trans. Jacob Gates (Boston, 1812; facs. repr. New York: Hafner, 1962), pp. vii, 279.

Cong, X., Ludington, S., McCain, G. and Fu, P. (2009). Kangaroo Care Modifies Preterm Infant Heart Rate Variability in Response to Heel Stick Pain: Pilot Study. Early human development. 85. 561-7.

Delacour, Jean. (2001) Proust's Contribution to the Psychology of Memory: The Reminiscences from the Standpoint of Cognitive Science. Theory \& Psychology Vol. 11. April 255-271.

Laennec, René T. H., A (1827). Treatise on the Diseases of the Chest and on Mediate Auscultation, trans. John Forbes, 2nd ed. London: Thomas and George Underwood. p. 549.

MacCain, G., Ludington-Hoe, S., Swinth, J., and Hadeed, A. (2005). Heart rate variability responses of a preterm infant to kangaroo care. Journal of obstetric, gynecologic, and neonatal nursing : JOGNN, 34(6), 689-694.

Merleau-Ponty, M. (1964). Eye and Mind. Trans Carleton Dallery. In: James M. Edie (ed), The Primacy of $P$ erception. Northwestern University Press. $159-90$.

Nancy, Jean-Luc (2002): Trans Susan Hanson. L'Intrus. CR: The New Centennial Review 2, no. 3 1-14. http://www.jstor.org/stable/41949352.

Shakespeare, William, 1564-1616. (2000). A.R. Braunmuller (ed). The merchant of $V$ enice. Penguin Group.

Kant, I. (I781). Critik der reinen Vernunft. Ed. Hartknoch. p. AXIV.

\footnotetext{
i Implemented for first time in Colombia in 1979 by Edgar Rey Sanabria and Héctor Martínez-Gómez as an alternative to conventional incubator treatment for low birth weight infants in
} 
Today is estimated that 82 percent of neonatal intensive care units use kangaroo care.

ii (author's translation) "Nach deren ausfuhrlicher kenntnisse ich nicht weit un mich suchen darf weil ich sie in mir selbt antreffe" 